Bangladesh J. Zool. 41(1): 105-112, 2013

\title{
EFFICACY OF SOME BOTANICALS AS INSECTICIDES ON THE MELON FLY, BACTROCERA CUCURBITAE (COQUILLETT) (DIPTERA : TEPHRITIDAE)
}

\author{
S. Sultana, A.F.M. Aslam*, F.A. Ahmed ${ }^{1}$ and A.J. Howlader \\ Department of Zoology, Faculty of Biological Sciences, \\ Jahangirnagar University, Savar, Dhaka-1342, Bangladesh.
}

\begin{abstract}
Efficacy of methanolic extracts of different indigenous plant parts, such as the leaves and barks of neem (Azadirachta indica); leaves of basil (Ocimum basilicum), mahua (Madhuca indica), lantana (Lantana camara), eucalyptus (Eucalyptus globulus), surjokonna (Spilanthes acmella) and flowers of golden shower (Cassia fistula), rosy periwinkle (Catharanthus roseus) and orchid (Mokara charkuan) were tested against the oviposition behavior of the melon fly, Bactrocera cucurbitae (Coquillett) (Diptera : Tephritidae). Most effective botanicals as attractants were observed in $C$. fistula and $M$. indica. In choice test, the percentage of B. cucurbitae pupae emerged were 0.0 in the leaves and barks of A. indica, 0.22 in flowers of $M$. charkuan, 1.43 in leaves of $O$. basilicum, 2.68 in leaves of $L$. camara, 6.83 in flowers of C. roseus, 5.51 in leaves of $S$. acmella, 13.27 in leaves of E. globules, 19.99 in flowers of $C$. fistula and 14.09 in leaves of $M$. indica. In nochoice test, the respective percentages of $B$. cucurbitae pupae emerged were 0.0, $2.19,2.29,11.68,10.65,12.34,7.73,6.76,13.66$ and 15.16 for the leaves of $A$. indica, bark of $A$. indica, in flowers of $M$. charkuan, in leaves of $O$. basilicum, in flowers of L. camara, in flowers of C. roseus, in leaves of S. acmella, in leaves of $E$. globules, in flowers of $C$. fistula and in leaves of $M$. indica. Phytochemical screening of the methanolic crude extracts of the botanicals showed that $M$. indica was strongly positive for steroid; C. fistula were strongly positive for alkaloid, flavonoids and glycoside and M. charkuan was weakly positive for carbohydrates, alkaloid and steroid.
\end{abstract}

Key words: Efficacy, insecticidal properties, botanicals, Bactrocera cucurbitae.

\section{INTRODUCTION}

The melon fly, Bactrocera cucurbitae (Coquillett) (Diptera: Tephritidae) is regarded as one of the most important global pest of quarantine importance. It is distributed widely in temperate, tropical, and sub-tropical regions of the world (Dhillon et al. 2005). More than 125 species of fruits and vegetables mostly belonging to the family Cucurbitaceae and Solanaceae have been recorded as hosts of B. cucurbitae. The extent of losses varies between $30 \%$ to $100 \%$, depending on the cucurbit species and the season (Sapkota et al. 2010). Generally, the females prefer to lay eggs in soft tender fruit tissues by piercing

"Author for correspondence. ${ }^{1}$ Department of Botany, Faculty of Biological Sciences, Jahangirnagar University, Savar, Dhaka - 1342, Bangladesh. 
piercing them with the ovipositor. Larval feeding in the fruits is the most damaging, as a result, young fruits become distorted and usually dropped. The larval tunnels provide entry points for bacteria and fungi that cause the fruit to rot. Because of the high egg laying capacity and mobility, each female is capable of destroying large numbers of fruit in her lifetime. In Bangladesh, B. cucurbitae represents $74 \%$ of the total number of flies infesting different vegetables growing areas (Akhtaruzzaman et al. 1999). The melon fly damages 10-30\% mangoes, star fruits and guava, and average $30-40 \%$ vegetables in Bangladesh every year (Wadud et al. 2005).

At present, the main aspect of the fly control program is based on the use of chemical insecticides. Traditional control measures using chemical insecticides experience disadvantages, such as pest resistance, residues in food, environmental contamination, outbreaks of secondary pests, reductions in populations of beneficial insects and inability of insecticides to penetrate infested fruits to kill larvae. Plant extracts are one of several non- chemical control alternatives that inspiring great interest due to their availability, reduced human and mammalian toxicity and friendliness to the environment (Aqil et al. 2010). There is no extensive report on the management of the melon fly, $B$. cucurbitae by using plant extracts. Neem (Azadirachta indica) is a key ingredient in non-pesticidal management (NPM), providing a natural alternative to synthetic pesticides. It acts as an anti-feedant, repellent, and egg-laying deterrent, protecting the crop from damage. Essential oil of basil (Ocimum basilicum) showed antifungal and insect-repelling properties (Dube 1989). Extracts of lantana (Lantana camara) may be used for the protection of vegetables against various insect pests (Shreth et al. 2009). The leaf extracts of eucalyptus (Eucalyptus globulus) shows efficacy against B. cucurbitae (Ali et al. 2011). Extracts from rosy periwinkle (Catharanthus roseus) have been used against numerous diseases and various insect pests (Toki et al. 2008). Therefore, present study was undertaken to assess the bioefficacy of the above plant extracts against the fly aiming to develop an ecofriendly and sustainable management system of the pest species.

\section{MATERIAL AND METHODS}

Preparation of plant extracts: Ten different botanicals, such as leaves and barks of neem (Azadirachta indica); leaves of basil (Ocimum basilicum), mahua (Madhuca indica), lantana (Lantana camara), eucalyptus (Eucalyptus globulus), surjokonna (Spilanthes acmella) and flowers of golden shower (Cassia fistula), rosy periwinkle (Catharanthus roseus) and orchid (Mokara charkuan) were collected from Jahangirnager University campus. Different parts of the plants 
were dried in an oven at $60-70^{\circ} \mathrm{C}$ for four hours and grinded separately using mortar and pastel. Each of the plant part was extracted for 8 hours successively with analytical grade methanol in a Soxhlet apparatus at $60^{\circ}-70^{\circ} \mathrm{C}$. The extracts obtained were then stored at $4^{\circ} \mathrm{C}$ keeping each in a separate conical flask. One gram of each crude extract was dissolved in $10 \mathrm{ml}$ methanol. Thus, 100 g crude extracts of each plant part were used for preparing $100 \mathrm{ml}$ stock solution.

Oviposition preference test: $B$. cucurbitae deposit their eggs inside the host tissue and the emerging larvae remain inside. It is difficult to count the number of larvae inside the food medium, therefore, the oviposition preference was calculated by counting the number of pupae emerged. Pieces of sweet gourds (Cucurbita maxima) were used as oviposition medium. Oviposition preference of the melon fly, $B$. cucurbitae was tested against the ten different types of plant extracts performing two types of tests- choice test and nonchoice test. The experiments were conducted in the laboratory of Entomology, Department of Zoology, Jahangirnagar University from October 2012 to December 2012.

Choice test: A whole sweet gourd was collected from the local market and cut into pieces each weighing about $200 \mathrm{~g}$. A total of 12 pieces of sweet gourds were prepared at a time. One piece of the sweet gourd was soaked with $5 \mathrm{ml}$ of a particular type of plant extract. Thus, there were 10 pieces of sweet gourd treated with the 10 different types of plant extracts. A piece of the sweet gourd was treated with $5 \mathrm{ml}$ of pure methanol and a piece was kept as untreated control. Each piece of the sweet gourd was then placed on a small petri dish. The pieces of the sweet gourd treated with different types of the plant extract, only methanol and fresh were randomly arranged inside the rearing cage $(76.2 \times$ $66 \times 76.2 \mathrm{~cm})$. Then 400 pairs of gravid adults were released into the rearing cage. After 24 hours of egg deposition, the pieces of sweet gourds along with the petri dishes were collected and then placed on a layer of saw dust (pupation media) inside a plastic bowl which was covered with thin clothes to permit pupation. After 2 to 3 days, plastic bowls were checked regularly for drop out of the rotting host-juice from the petri-dish to avoid the unnatural death of larvae. After 6-8 days, pupae were collected by sieving the saw dust. The same experiment was replicated three times. The total number of pupae produced from each type of sweet gourd was counted, recorded and compared with each other.

Nonchoice test: The oviposition preference tests in non-choice condition with each type of plant extract was conducted with three pieces (each weighing $200 \mathrm{~g}$ ) of sweet gourd. Each piece of the sweet gourd was treated with $5 \mathrm{ml}$ of a particular plant extract individually. Each piece of the sweet gourd was then placed on a small petri dish. All petri dishes along with pieces of sweet gourd 
were then distributed into small $(31 \times 12 \times 31 \mathrm{~cm})$ rearing cage. Then 25 pairs of gravid melon fly were released into each cage and allowed for deposition of eggs for 24 hours. A similar set of experiment was conducted using fresh piece of sweet gourds as untreated control. To find out the effect of solvent (if any) on the oviposition of the fly, a separate set of treated control experiments was conducted with the same volume of solvent only. The number of pupae produced from each piece of sweet gourd was counted and recorded following the same procedure as mentioned above in case of choice tests.

Phytochemical screening: The crude plant extracts were subjected to different qualitative tests to find out the presence of following chemical constituents: carbohydrates, alkaloids, glycerides, flavonoids, phenoles, terpenoids, steroids and saponins. These were identified by characteristic color changes using standard tests following Trease and Evans (1989), Sofowora (1993) and Evans (2002).

Statistical analysis: Data obtained from the experiments were statistically analyzed through ANOVA at RCBD (1 factor) design. Since F-test was significant, means were separated using Duncan's Multiple comparison Range Tests at $0.05 \%$ level of significance using MSTAT-C statistical program.

\section{RESULTS AND DISCUSSION}

Oviposition preference test: In choice test (Table 1), pupal yield of $B$. cucurbitae was higher from C. fistula (2982) treated host followed by methanol (2742), control (2624), M. indica (2102), E. globulus (1979), C. roseus (1018), S. acmella (822), L. camara (399), O. basilicum (214), and M. charkuan (33). It was zero $(0)$ in case of $A$. indica leaf and bark extracts. Significantly $(p<0.01)$ higher pupal production was recorded in case of C. fistula. Whereas, C. fistula was found to be most preferred/susceptible boatanical for $B$. cucurbitae while considering mean pupal production from the natural host treated with different botanicals under controlled laboratory conditions. A. indica extracts treated hosts appeared as least preferred.

In nonchoice test (Table 1), the highest (1019) number of $B$. cucurbitae pupa were produced from only methanol treated hosts. M. indica (881) showed second highest susceptible botanical followed by control (797), C. fistula (794), C. roseus (717), O. basilicum (679), L. camara (619), S. acmella (449), E. globulus (393), M. charkuan (133) and A. indica bark (127) in terms of pupal yield. Significantly $(\mathrm{P}<0.05)$ higher pupal production was recorded in case of $M$. indica. Pupal production was also zero $(0)$ in case of $A$. indica leaf extract treated hosts. 
Table 1. Number of Bactrocera cucurbitae pupae emerged from fresh, methanol treated and methanol extracts of different botanicals treated hosts in choice and non-choice tests

\begin{tabular}{lcccc}
\hline \multirow{2}{*}{ Treatments } & \multicolumn{2}{c}{ Choice test } & \multicolumn{2}{c}{ Non-choice test } \\
\cline { 2 - 5 } & $\begin{array}{c}\text { Total pupae } \\
\text { produced }\end{array}$ & Mean $\pm \mathrm{SE}$ & $\begin{array}{c}\text { Total pupae } \\
\text { produced }\end{array}$ & Mean $\pm \mathrm{SE}$ \\
\hline Fresh & 2624 & $874 \pm 85.16^{\mathrm{a}}$ & 797 & $265.67 \pm 10.97 \mathrm{a}$ \\
Methanol & 2742 & $914 \pm 314.21^{\mathrm{a}}$ & 1019 & $339.67 \pm 7.22^{\mathrm{ab}}$ \\
M. indica & 2102 & $700.67 \pm 114.89 \mathrm{a}$ & 881 & $293.67 \pm 7.80^{\mathrm{bc}}$ \\
C. fistula & 2982 & $994.00 \pm 170.90 \mathrm{ab}$ & 794 & $264.67 \pm 43.05_{\mathrm{bc}}$ \\
E. globulus & 1979 & $659.67 \pm 12.99 \mathrm{ab}$ & 393 & $131.00 \pm 32.33_{\mathrm{bc}}$ \\
S. acmella & 822 & $274.00 \pm 71.01 \mathrm{bc}$ & 449 & $149.67 \pm 48.21_{\mathrm{bc}}$ \\
C. roseus & 1018 & $339.33 \pm 57.45^{\mathrm{c}}$ & 717 & $239.00 \pm 17.62^{\mathrm{cd}}$ \\
L. camara & 399 & $133.00 \pm 6.81^{\mathrm{c}}$ & 619 & $206.33 \pm 15.60 \mathrm{de}$ \\
O. basilicum & 214 & $71.33 \pm 1.76^{\mathrm{c}}$ & 679 & $226.33 \pm 35.22^{\mathrm{e}}$ \\
M. charkuan & 33 & $11.00 \pm 0.58^{\mathrm{c}}$ & 133 & $44.33 \pm 23.45^{\mathrm{f}}$ \\
A. indica (bark) & zero & zero & 127 & $42.33 \pm 2.60^{\mathrm{f}}$ \\
A. indica (leaf) & zero & zero & zero & zero \\
\hline
\end{tabular}

Table 1 revealed that lowest number of $B$. cucurbitae pupae were produced from $A$. indica treated hosts. This finding has similarity to the result of Mahmoud and Shoeib (2008) who showed that low concentrations of neem can be applied effectively as sterilant and oviposition deterrent for the peach fruit fly populations. It is pertinent to mention here that the findings of Mahfuza et al. (2007) they reported that the Neem blocks the ovarian development and can be used as safe alternative of insecticides for the control of Bactrocera species. Orchid, M. charkuan treated host also produced least number of pupae in both choice and nonchoice tests and acted as oviposition deterrent for B. cucurbitae. The result conflict the findings of Nishida et al. (2004) in that the flowers of a Southeast Asian orchid, Bulbophyllum cheiri, attract males of Bactrocera papayae and other fruit fly species sensitive to methyl eugenol for pollination. Crude extracts of basil (O. basilicum) leaf also deterred the oviposition of female melon fly and pupal production was minimum. These result shows similarities with the findings of Chang et al. (2009) who reported that several varieties of $O$. sanctum and $O$. basilicum contain different amounts of methyl euginol in their essential oils and methyl eugenol is very toxic to $C$. capitata and B. cucurbitae, but less toxic to $B$. dorsalis to which methyl eugenol is a male lure. The toxic action of basil oil in $B$. cucurbitae occurred significantly faster than in $B$. dorsalis.

Phytochemical screening: Data presented in Table 2 represent the qualitative chemical analysis of methanolic crude extracts of leaf, bark and flowers of relatively effective botanicals, either as attractant or deterrent. Preliminary phytochemical screening showed that leaf extract of $M$. indica contained 
carbohydrate, alkaloid, flavonoid, phenolic compounds and steroid; extracts from the flower of $C$. fistula contained carbohydrate, alkaloid, flavonoid, glycoside, saponin and steroid; flower extracts of $M$. charkuan contained carbohydrate, alkaloid, glycoside and steroid. All these compounds (viz. carbohydrates, glycoside, steroids, tannins, alkaloids and flavonoids) are known to be biologically active and therefore aid in insecticidal activities. These secondary metabolites exert insecticidal activity through different mechanisms. Shimada (2006) reported tannins to form irreversible complexes with proline rich protein resulting in the inhibition of cell protein synthesis. Steroidal compounds are of importance and interest due to their relationship with various anabolic hormones including sex hormones (Okwu 2001). Different parts of plants contain the toxic alkaloid esters which prevent insects from feeding on these. Hence, the presence of these compounds in the said botanicals corroborates the insecticidal activities observed.

Table 2. Qualitative chemical examination of the methanolic crude extracts of different plants showing the preferences to the Bactrocera cucurbitae

\begin{tabular}{|c|c|c|c|c|c|}
\hline Tests for & \multicolumn{2}{|l|}{ Specific test } & $\begin{array}{l}\text { Leaf of } \\
M . \text { indica }\end{array}$ & $\begin{array}{l}\text { Flower of } \\
\text { C. fistula }\end{array}$ & $\begin{array}{c}\text { Flower of } M \text {. } \\
\text { charkuan }\end{array}$ \\
\hline Carbohydrate & \multicolumn{2}{|c|}{ Molish reagent test } & - & + & + \\
\hline \multirow{7}{*}{ Alkaloid } & \multicolumn{2}{|c|}{ Fehling's reagent test } & + & + & + \\
\hline & \multicolumn{2}{|c|}{ Hager's reagent. } & - & + & + \\
\hline & \multicolumn{2}{|l|}{ Wagner's reagent. } & + & +++ & + \\
\hline & \multicolumn{2}{|l|}{ Mayer's reagent. } & + & + & + \\
\hline & \multicolumn{2}{|c|}{ Dragendorff's reagent. } & ++ & + & - \\
\hline & \multicolumn{2}{|c|}{ Tannic acid (10\%) } & ++ & + & + \\
\hline & \multicolumn{2}{|c|}{ Ferric Chloride $\left(\mathrm{FeCl}_{3}\right)$ test } & + & + & - \\
\hline \multirow[t]{4}{*}{ Flavonoid } & \multicolumn{2}{|c|}{ Lead Acetate test } & + & + & - \\
\hline & \multicolumn{2}{|l|}{ Alkali test } & + & - & - \\
\hline & \multicolumn{2}{|c|}{ Con. $\mathrm{H}_{2} \mathrm{SO}_{4}$ treatment } & ++ & +++ & + \\
\hline & Common test & Ferric Chloride $\left(\mathrm{FeCl}_{3}\right)$ test & - & + & +++ \\
\hline \multirow[t]{3}{*}{ Glycoside } & $\begin{array}{l}\text { Anthraquinon } \\
\text { Glycosides test }\end{array}$ & Borntragers test & - & - & ++ \\
\hline & $\begin{array}{l}\text { Cardiac } \\
\text { Glycosides test }\end{array}$ & Keller killiani test & + & + & - \\
\hline & \multicolumn{2}{|c|}{ Ferric Chloride $\left(\mathrm{FeCl}_{3}\right)$ test } & + & + & - \\
\hline \multirow{3}{*}{$\begin{array}{l}\text { phenolic } \\
\text { compounds } \\
\text { \& tannins }\end{array}$} & \multicolumn{2}{|c|}{ Lead Acetate test } & + & - & - \\
\hline & \multicolumn{2}{|l|}{$\mathrm{HNO}_{3}$ test } & - & - & - \\
\hline & \multicolumn{2}{|l|}{ Amonia $\left(\mathrm{NH}_{3}\right)$ test } & ++ & - & + \\
\hline Saponin & & Foam test & - & - & - \\
\hline \multirow{2}{*}{ Terpenoid } & Common test & Con. $\mathrm{H}_{2} \mathrm{SO}_{4}$ test & - & - & ++ \\
\hline & Triterpenoids test & Acetic anhydride test & - & - & +++ \\
\hline $\begin{array}{l}\text { Phytosterol/ } \\
\text { Steroid }\end{array}$ & \multicolumn{2}{|l|}{ Salkowski test } & +++ & ++ & + \\
\hline
\end{tabular}

$+++=$ Highly preferred, $++=$ Moderately preferred, $+=$ Least preferred, $-=$ No preference . 
However, from the overall findings, we may conclude that $M$. indica and $C$. fistula were the most preferred botanicals to be considered for the control of the melon fly. As far as the production of pupae is concerned, the leaf and bark of $A$. indica, leaf of basil $O$. basilicum and flowers of $M$. charkuan extracts have high oviposition deterrent effect. Experimental results might be useful in developing phytochemical bait to attract and killing technique to combat against the melon flies. Besides traditional ways, it assumes that the further advancement of this work will be most promising to us that may lead to open new door for the future control strategies to solve the melon fly problem.

Acknowledgements: We are grateful to the Ministry of Science and Technology, Government of the People's Republic of Bangladesh for providing a grant under which the present research work was carried out.

\section{LITERATURE CITED}

AKHTARUZZAMAN, M., ALAM, M.Z. and SARDAR, M.A. 1999. Identification and distribution of fruit flies infesting cucurbits in Bangladesh. Bangladesh J. Entomol. 9: 93-101.

ALI, H., AHMAD, S., HASSAN, G., AMIN, A., HUSSAIN, Z. and NAEEM, H. 2011. Bio efficacy of different plant extracts against Melon fruit fly in bitter gourd. Pakistan J. Weed Sci. Res. 17(2): 143-149.

AQIL, F., ZAHIN, M., AHMED, I., OWAIS, M. and SAJJAD, M. 2010. Antifungal activity of medicinal plant extracts and phytocompounds: A review. In: Ahmed, I., Owais, M., Shahid, M. (Eds.) Combating fungal infections: Problem and remedy. Springer- Verlag, Berlin Heidelberg, pp. 449485.

CHANG, C.L., CHO, I.K. and LI, Q.X. 2009. Insecticidal activity of basil oil, trans-anethole, estragole, and linalool to adult fruit flies of Ceratitis capitata, Bactrocera dorsalis, and Bactrocera cucurbitae. J. Econ. Entomol. 102(1): 203-209.

DHILLON, M.K., NARESH, J.S., SINGH, R. and SHARMA, H. C. 2005. The melon fruit fly, Bactrocera cucurbitae: A review of its biology and management. J. Insect Sci. 5: 1-16.

DUBE, S. 1989. Antifungal, physicochemical, and insect-repelling activity of the essential oil of Ocimum basilicum. Pakistan J. Weed Sci. Res. 2: 23-25.

MAHFUZA, K., HOSSAIN, A.M. and ISLAM, S.M. 2007. Effects of neem leaf dust and a commercial formulation of a neem compound on the longevity, fecundity and ovarian development of the melon Fly, Bactrocera cucurbitae (Coquillett) and the oriental fruitfly, Bactrocera dorsalis (Hendel) (Diptera:Tephritidae). Pakistan J. Biol. Sci. 10: 3656-3661.

MAHMOUD, M.F. and SHOEIB, M.A. 2008. Sterilant and oviposition deterrent activity of neem formulation on Peach fruit fly Bactrocera Zonata (Saunders) (Diptera: Tephritidae). J. Biopes. 1(2): 177-181.

NISHIDA, R., TAN, K.H., WEE, S.L., HEE, A.K.W. and TOONG, Y.C. 2004. Phenylproponaids in the fragrance of the fruit fly orchid, Bulbophyllum cheiri, and their relations to the pollinator, Bactrocera papaya. Biochem. Sys. Ecol. 32(3): 245-252.

OKWU, D.E. 2001. Evaluation of the chemical composition of indigenous spices and flavouring agents. Global J. Appl. Sci. 7(3): 455-459. 
SAPKOTA, R., DAHAL, K.C. and THAPA, R.B. 2010. Damage assessment and management of cucurbit fruit files in spring-summer squash. J. Entomol. Nematol. 2(1): 7-12.

SHIMADA, T. 2006. Salivary proteins as a defense against dietary tannins. J. Chem. Ecol. 32(6): 1149-1163.

SHRETH, C.N., IBOHAL, K. and WILLIAM, S.J. 2009. Laboratory evaluation of certain cow urine extracts of indigenous plants against mustard aphid, Lipaphis erysimi (Kaltenbach) infesting cabbage. Hexapoda. 2: 11-13.

SOFOWORA, A. 1993. Medicinal plants and traditional medicine in Africa. John Wiley and Son Ltd., pp. 150-153.

TOKI, K., SAITO, N., IRIE, Y., TATSUZAWA, F., SHIGIHARA, A. and HONDA, T. 2008. 7-OMethylated anthocyanidin glycosides from Catharanthus roseus. Phytochem. 69(5): 1215-1219.

TREASE, G.E. and EVANS, W.E. 1989. Pharmaccology, 11th Eds. Brailliar Tiridel and Macmillian Publishers, London. pp. 17-23.

WADUD, M.A., HOSSAIN, M.A. and ISLAM, M. 2005. Sensitivity of the melon fly, Bactrocera cucurbitae (Coq.) pupae to gamma radiation. Nucl. Sci. Appl. 14: 119-122.

(Manuscript received on 21 May 2013; revised on 22 June 2013) 